\title{
Nem Refugiados, nem Migrantes: A Chegada dos Haitianos à Cidade de Tabatinga (Amazonas)
}

\author{
Jean-François Véran ${ }^{1}$ \\ Débora da Silva Noal ${ }^{2}$ \\ Tyler Fainstat ${ }^{3}$
}

${ }^{1}$ Instituto de Filosofia e Ciências Sociais (IFCS), Universidade Federal do Rio de Janeiro (UFRJ), Rio de Janeiro, RJ, Brasil. E-mail: ffveran@gmail.com.

${ }^{2}$ Universidade de Brasília, Brasília, DF, Brasil. E-mail: noaldebora@gmail.com.

${ }_{3}^{3}$ John Howard Society, Kingston, Ontário, Canadá. E-mail: tfainstat@gmail.com

$\mathrm{O}$

Brasil, que se constitui em um país de migrantes, iniciou, após a década de 1930, um conjunto de políticas restritivas que dificultou a entrada de imigrantes e refugiados. Passado o período da escravidão, consolidou-se o último grande fluxo migratório, que tem seu início no fim do século XIX e seu término na década de 1920. Fora estimulado e organizado um conjunto de políticas públicas que facilitavam a entrada, a legalização e a instalação dos recém-chegados, essencialmente para suprir as necessidades de mão de obra nas plantações de café de São Paulo. Nessas migrações "desejadas", era privilegiada a "ascendência europeia", tida como garantia de um povoamento compatível com uma visão de civilização dominada pelo imaginário europeu.

A partir de 1933, a imigração foi regulada de forma restritiva pela Constituinte (Geraldo, 2009). Foi determinado, então, que o Brasil receberia anualmente um número máximo de $2 \%$ do total de imigrantes da cada nacionalidade que tivessem imigrado nos últimos 50 anos. Passou-se, desse modo, da promoção de fluxos coletivos das décadas anteriores a uma gestão restritiva de trajetórias individuais seletivamente indesejáveis. Desde então, e apesar de sua reformulação na década de 1980, a lei brasileira de imigração continua determinada pelo paradigma minimalista da porta estreita, não sendo estabelecidas políticas migratórias proativas, as quais definiriam o posicionamento do Brasil dentro das dinâmicas migratórias globalizadas.

DADOS - Revista de Ciências Sociais, Rio de Janeiro, vol. 57, no-4, 2014, pp. 1007 a 1041.

http://dx.doi.org/10.1590/00115258201431 
Neste início de século XXI, os deslocamentos em larga escala se multiplicam com a velocidade dos meios modernos de comunicação. Amplas transformações geopolíticas, climáticas e econômicas impactam realidades demográficas de continentes inteiros. Nesse contexto, $\mathrm{o}$ Brasil surge como uma potência econômica politicamente estável e com uma diplomacia abertamente desafiadora das políticas restritivas do Ocidente: cooperação Sul-Sul, militante da quebra de algumas patentes médicas (por razões humanitárias), protagonista da missão de paz no Timor e artesão central da intervenção das Nações Unidas no Haiti. Nessa conjuntura, era de se esperar que o Brasil entraria na rota das migrações globalizadas. Entretanto, quando, do início de 2010 a março de 2012, se deu um inédito fluxo de aproximadamente 4 mil migrantes haitianos na região Norte (Acre e Amazonas), evidenciaram-se os limites da capacidade de resposta legal e operacional nos níveis municipal, estadual e federal.

Com base no estudo de caso da cidade de Tabatinga (AM), que recebeu 3 mil desses migrantes, este artigo propõe descrever e analisar as dificuldades de assistência e proteção vivenciadas pela população haitiana durante a intervenção de uma organização humanitária internacional (Médicos Sem Fronteiras - MSF) entre outubro de 2011 e março de 2012. Os dados aqui apresentados resultam de uma pesquisa preliminar realizada entre setembro e outubro de 2011. Nesta ocasião, um questionário foi aplicado em crioulo a 180 migrantes ( $24 \%$ da população haitiana total que se encontrava na cidade no momento da pesquisa). Ademais, foram constituídos três grupos focais e realizadas 18 entrevistas semidiretivas com migrantes, além de discussões com autoridades e atores locais ${ }^{1}$. Em Manaus, entrevistas semidiretivas foram realizadas com parlamentares, representantes da Polícia Federal e atores do sistema público de saúde. Em Brasília, entrevistas semidiretivas foram realizadas com responsáveis do Conselho Nacional de Imigração (CNIG), do Comitê Nacional para os Refugiados (Conare), e do Alto Comissariado das Nações Unidas para os Refugiados (Acnur). Considerando-se a experiência de MSF em questões migratórias adquirida em diferentes projetos nos últimos 40 anos, o intuito aqui é trazer elementos que possam alimentar a reflexão sobre a política migratória do Brasil.

\section{TABATINGA À LUZ DA NOÇÃO DE “EVENTO CRÍTICO”}

Partiremos do princípio de que a migração haitiana em Tabatinga, em seu auge, entre junho de 2011 e fevereiro de 2012, constituiu-se em um "evento crítico" na história migratória brasileira. 
No que concerne a "evento crítico", tomaremos emprestadas de François Furet as ideias de "singularidade" e de "erupção" de uma "nova modalidade de ação histórica" (Furet, 1978). Pode-se supor que, no decorrer dos últimos 20 anos, outros movimentos migratórios (colombianos, bolivianos...) já haviam desafiado o dogma do controle dos fluxos; porém, amplamente confinadas à informalidade de relações entre países vizinhos, elas não haviam impactado as políticas públicas migratórias (Baeninger, 2012). No caso da migração haitiana, por meio de seu desenvolvimento político e midiático, surgiu ainda como um evento na ordem do imaginário (Furet, 1978), ativando ou reativando um conjunto de representações que conferem ao evento seu status como tal. "O Haiti é aqui" funcionou como um operador sintético entre registros que foram do humanitarismo internacional a medos romantizados do haitianismo do século XIX (medo da contaminação política da revolução haitiana), passando pela reativação do poderoso imaginário da "África no Brasil" (Fry e Vogt, 1996).

Como segundo ponto de estudo, retemos o conceito de "evento crítico" de Veena Das (1995), o qual comporta a ideia de que a análise de determinados eventos permite apontar para realidades sociopolíticas complexas, articulando escalas local, nacional e internacional. De fato, se os casos microlocais de Tabatinga (no Amazonas) ou de Brasileia (no Acre) acabaram por configurar uma questão nacional, é tanto pela complexidade da conjuntura quanto pela estratégia de resposta técnico-legal, além da forma com que o Estado apropriou-se do "caso dos haitianos" para enunciar uma excepcionalidade e reafirmar uma norma migratória: atribuir vistos "humanitários" aos haitianos já em solo brasileiro, enfocando, assim, a legitimidade internacional do Brasil, bem como sua "generosidade", e tentar voltar a um regime restritivo de cotas para garantir uma imigração de qualidade ou "escolhida".

Ao resgatar em seus detalhes o caso particular de Tabatinga, acompanhamos Veena Das em seu cuidado de "resgatar os momentos perdidos" pela narrativa nacional e restituir algo da verdade das pessoas envolvidas, concordando com ela que tal escuta abre para novas possibilidades de justiça (1995).

Finalmente, a situação de Tabatinga será apreendida aqui pelo prisma operacional de uma organização humanitária médica de emergência (MSF). Vale ressaltar que este artigo não é um exercício de comunicação institucional na forma de um documento de advocacia, tal como a 
organização procede quando da atuação em determinado contexto, mas, sim, uma publicização, na medida em que o trabalho realizado torna a organização testemunha privilegiada dos acontecimentos narrados.

Trata-se aqui de um trabalho de pesquisa operacional, cujo objetivo é produzir conhecimentos sobre intervenções, estratégias ou ferramentas que possam melhorar a qualidade, a efetividade e a cobertura dos programas nos quais a pesquisa é conduzida (MSF, 2010). Nesse caso, tal pesquisa se justificou pelo caráter inédito no contexto brasileiro da situação que motivou a decisão da organização de lançar um projeto pontual de assistência para os migrantes haitianos de Tabatinga. De fato, vale registrar que, salvo em contextos de catástrofes naturais (Alagoas, 2010; Rio de Janeiro, 2011), MSF não desenvolve projetos no Brasil desde 2009, o que ressalta essa excepcionalidade percebida na situação de Tabatinga aos olhos da organização.

No momento em que a pesquisa foi iniciada, e baseando-se em sua experiência dos fluxos migratórios em várias regiões do mundo, acreditava-se também na dimensão exemplar de Tabatinga, no sentido de que tal situação prefigurava potencialmente um novo polo de tensão migratória com riscos humanitários. A pesquisa operacional buscou, por esse motivo, evidenciar as dinâmicas que compuseram em Tabatinga uma "situação humanitária".

\section{Tabatinga, uma Situação Humanitária}

Tabatinga está localizada na tríplice fronteira Peru/Brasil/Colômbia, na região amazônica, com uma população de cerca de 50 mil habitantes. A "fronteira seca" com a cidade colombiana de Letícia e a fronteira aberta com a ilha peruana de Santa Rosa fazem da cidade um lugar de nomadismo intersticial. Comércio, casamentos, vida noturna: as populações transitam entre os três países em um território socialmente contínuo. A esse fluxo de fronteira somam-se as idas à cidade das populações indígenas vizinhas e a rotatividade do contingente militar, importante em razão da localização estratégica de Tabatinga.

Nesse contexto, tecido por incessantes trajetórias individuais e coletivas, a chegada dos haitianos não constituiu uma ruptura na rotina de um povoado isolado da Amazônia, apenas mais fluxo em uma cidade de fluxos. Isso talvez explique a relativa serenidade com a qual a população local recebeu os migrantes haitianos, os quais ressaltaram a cor- 
dialidade do acolhimento e avaliaram o "primeiro contato" como globalmente bom.

Contudo, rapidamente os migrantes compuseram uma "minoria visível", e a cor da pele, assim como o "imaginário" do Haiti, não foram os únicos elementos de destaque. Como quaisquer migrantes recémchegados, sua visibilidade decorreu de sua precariedade (Noiriel, 1988): ocupação ociosa dos espaços públicos, forte presença nos serviços de assistência e na Polícia Federal, incorporação marginal nos subempregos informais (venda de jornais, estivadores do porto...). Não faltaram espaços onde a visibilidade apontou para as necessidades múltiplas de uma população inesperada.

No entanto, Tabatinga mostrou-se constitutiva de poucos recursos para suprir as necessidades básicas de uma população migrante excepcionalmente precária, assim como veremos a seguir. No momento em que a pesquisa foi realizada, a cidade tem uma estrutura sanitária insuficiente mesmo para a população local. Apesar de ser banhada por um dos maiores rios do mundo, o Solimões, sofre pela falta constante de água para o consumo humano. A disposição geográfica e a distância marcam a relação com a capital do estado, complicando tanto a visibilidade política quanto a alocação dos recursos: a cidade só é acessível por via aérea (voos diários de Manaus) ou vias fluviais (de barco, sete dias no sentido Manaus-Tabatinga e três dias no sentido Tabatinga-Manaus). Tabatinga possui um hospital militar (cofinanciado pelo Sistema Único de Saúde - SUS) frequentemente sobrecarregado com pacientes oriundos do próprio município e das cidades adjacentes. A população vive, majoritariamente, na precariedade, decorrendo de um mercado local reduzido, com poucas oportunidades e rendas baixas.

\section{Haitianos em Tabatinga}

Entre os anos 2010 e 2012, a Polícia Federal brasileira contabilizou a entrada de 3.814 haitianos (456 em 2010; 1.898 em 2011 e 1.460 apenas no mês de janeiro de 2012). Esses haitianos exploravam uma nova rota de diáspora. Nesse momento, as terras de migração tradicional - EUA, Canadá, Europa - apresentavam-se com suas fronteiras fechadas ou fechando, à medida que se esgotava o argumento humanitário de abertura que se seguiu ao período pós-terremoto no Haiti, em janeiro de 2010. A pesquisa quantitativa realizada em Tabatinga no mês de setem- 
bro de 2011 apontou que 30\% dos migrantes que chegaram à cidade entre setembro e outubro desse ano estavam saindo da República Dominicana, onde se queixavam de rendas baixas e múltiplas discriminações. No Equador, só podiam circular de forma transitória mediante a assinatura de um documento, tendo, inclusive, o direito ao casamento negado.

A complexidade do percurso vivenciado até chegar a Tabatinga reflete bem essa geopolítica de barragens. Os migrantes não podiam entrar diretamente no Brasil por falta das condições necessárias à obtenção do visto. Da mesma maneira, uma vez que entravam sem visto, não podiam solicitar o Estatuto de Migrante Econômico, restando apenas a possibilidade de solicitar o Estatuto de Refugiado, condicionado ao fato de entrar no Brasil a partir de um país fronteiriço, acarretando a impossibilidade de acesso por via aérea direta.

As condições descritas explicam por que a viagem era tão segmentada: do Haiti, o migrante precisava ir até a República Dominicana, de onde embarcava para o Panamá ou para o Equador (de avião, três a quatro horas de viagem); em seguida, acontecia a viagem de ônibus (24 horas) ou de avião (uma hora) até Iquitos, no Peru; daí, um percurso de barco de 24 horas o levava até Tabatinga.

O pioneirismo do percurso ainda era agravado pelas condições financeiras de sua execução. Enquanto, pelas tarifas oficiais, o custo médio dessa viagem devia estar abaixo de US $\$ 2,000$, incluindo despesas (hotel, alimentação), apenas $17 \%$ dos migrantes entrevistados declararam pagar esse valor ou um pouco acima (até US\$ 2,400): 65\% pagaram mais de US\$1,000 acima do previsto. O custo adicional era causado pela presença de atravessadores (coiotes), que atuavam em todos os pontos da rota; $42 \%$ dos migrantes entre setembro e outubro de 2011 espontaneamente relataram a presença de coiotes atuando em todo o percurso do Haiti ao Brasil. Relatou-se, ainda, que os coiotes baseavam-se no Haiti, Equador, Peru e Brasil (em Tabatinga, onde a Polícia Federal chegou a prender um homem acusado de tráfico de seres humanos).

Além de coagidos ao longo da viagem, o dinheiro dos migrantes também havia sido "capturado" em sua fonte: na maioria dos casos, ele fora obtido pela venda de terras e gado da família e, sobretudo, por meio de empréstimos contraídos no Haiti, onde parte da família que ficara permanecia como garantia à espera de remessas financeiras 
oriundas da aposta e do investimento feito por um dos membros da família. Ecoando com outras realidades já relatadas na antropologia das migrações (Sayad, 1975), longe de se constituir em uma aventura individual, a vinda para o Brasil inscreve-se em uma rede densa de deveres e obrigações. Assim, para os haitianos, a descoberta do Brasil nas condições precárias de Tabatinga foi logo marcada pela angústia de um sentimento de dívida incompensável. A realidade, rapidamente revelada, do salário mínimo no Brasil sobrecarrega essa sensação de grande desilusão.

Em suas crônicas da servilidade na Amazônia brasileira, Christian Geffray, Neide Esterci e Ricardo Figueira mostram o quanto relações de sujeição mantidas com violência e dívidas imaginárias marcam profundamente o modelo social da região amazonense (Geffray, 1995; Esterci e Figueira, 2007). E por que não dizer que, do parentesco haitiano ao paternalismo local, migrantes haitianos e população tabatinguense tinham em comum o ethos da sujeição.

No entanto, os primeiros contatos foram marcados por equívocos que mascararam essa relativa comunidade de destino. Em uma região desprovida economicamente, como a Tabatinga, a importância dos valores pagos pelos haitianos para a viagem levou à percepção de que eles tinham dinheiro e, por isso, não precisavam de ajuda. Ressalta-se aqui um detalhe irônico dessa percepção: aos olhos da população local, os haitianos andavam bem vestidos demais para serem qualificados como necessitados. Os tabatinguenses não imaginavam que as roupas haviam sido compradas em feiras de segunda mão nos mercados de rua do Haiti (em média US $\$ 4$ a peça) e de pontas de estoque oriundas dos EUA, as quais chegam inicialmente como ajuda humanitária.

Dadas essas condições, não é de se estranhar que os migrantes chegassem a Tabatinga com poucos recursos financeiros para suportar os dois/três meses de espera que o processo de solicitação do status de refugiado havia demandado.

\section{Uma Migração de Trabalho}

O perfil socioeconômico dos migrantes, tal como fora estabelecido na base da pesquisa quantitativa realizada por Médicos Sem Fronteiras entre setembro e outubro, ressalta mais ainda a condição de vulnerabilidade na qual se realizou a migração. Dentre os migrantes entrevistados, $63 \%$ possuíam entre 25 e 35 anos de idade, com uma idade média 
de 30 anos - em um país (Haiti) onde a população média é de 18 anos e a expectativa de vida é de 60 anos, os migrantes estavam predominantemente em sua meia-idade; $70 \%$ eram homens e 30\%, mulheres; $71,5 \%$ dos homens e $62 \%$ das mulheres tinham filhos, e apenas 3\% haviam viajado para Tabatinga com pelo menos um de seus filhos; $46 \%$ eram casados, $44 \%$, solteiros, e $38 \%$ dos solteiros haviam deixado filhos no Haiti.

A grande maioria dos migrantes tinha uma família que dependia deles; $24 \%$ haviam cursado até o primeiro grau e $59 \%$, até o segundo; enquanto $5 \%$ haviam cursado a universidade, apenas $2 \%$ tinham um diploma universitário - considerando que no Haiti apenas 33\% da população cursam o segundo grau, o grau de escolaridade dos migrantes era maior do que a média do país. Esse indicador se explica sobretudo, pelo efeito de classe de idade, já que se trata de uma migração relativamente jovem; $47 \%$ dos homens trabalhavam na construção civil, principalmente como pedreiros; $7 \%$ eram motoristas; $6 \%$, mecânicos; as mulheres possuíam experiência profissional principalmente no comércio (33\%) e/ ou como costureiras (25\%). Esse quadro aponta para a baixa qualificação dos migrantes, com consideráveis exceções, tais como um economista, um contador e um jornalista. É notável que apenas 3\% dos migrantes relataram ser camponeses. Trata-se claramente de uma migração urbana.

Boa parte dos migrantes (70\%) declararam ter sido afetados pelo terremoto: $33 \%$ perderam um membro da família e $51 \%$ tiveram suas casas destruídas. Ressalta-se que a importância das perdas familiares reforça a responsabilidade dos membros sobreviventes e que a relevância da destruição da casa aponta para uma situação de pouca autonomia no país de origem. Essa observação é reforçada pela percepção dos migrantes: $56 \%$ referiram-se ao terremoto como uma motivação para a migração. É notável que a falta de trabalho é, de longe, o principal fator alegado (84\%), mas esse fator não é independente, uma vez que estava relacionado com o terremoto, a pobreza $(40 \%)$ e a insegurança/medo $(41 \%)$.

É interessante observar que, se existe uma forte correlação entre a migração e o terremoto, esta não é independente, uma vez que não leva em conta uma realidade invisível: nenhum ou poucos migrantes vinham das regiões severamente afetadas. Por exemplo, pouquíssimas 
pessoas oriundas da região de Léogâne foram contabilizadas, ainda que a cidade tivesse $80 \%$ de seu território destruído.

Quanto ao deslocamento, $62 \%$ haviam viajado com amigos ou familiares e $8 \%$, com outros haitianos. Esses dados evidenciam uma migração coletivamente planejada e efetuada, obedecendo a uma forte lógica de rede. Essa pode ser a explicação principal para a distribuição geográfica desigual da origem dos migrantes. O terremoto é um fator, mas a existência de uma rede transforma a situação objetiva em uma oportunidade subjetiva.

O tratamento midiático e político foi dominado pela ideia de que "os imigrantes haitianos que chegam ao Brasil são profissionais qualificados, oriundos da classe média, como engenheiros, professores, advogados, pedreiros, mestres de obras e carpinteiros"'2. Os dados apontam para um padrão bastante diferente: trata-se de uma migração de trabalho carregando consigo a realidade dominante no Haiti: a de uma população pouco qualificada e assolada por múltiplas vulnerabilidades.

\section{As Condições de Vida}

Em muitos contextos em que fluxos migratórios se dão com populações em situações precárias (Quênia, Sudão, Líbia, Malta...), programam-se mecanismos de assistência e proteção por parte ora de instituições públicas, ora de redes densas de organizações não governamentais e organismos internacionais. No entanto, como veremos na segunda parte deste texto, não foi esse o caso de Tabatinga. Com exceção de medidas paliativas da Pastoral da Mobilidade Humana (igreja católica local), que disponibilizou recursos para auxiliar na assistência emergencial logo após a chegada desses haitianos, não houve outros dispositivos de assistência para esse fluxo de migrantes. Estes se encontraram entregues à realidade áspera de uma pequena cidade fronteiriça da Amazônia e contaram principalmente consigo mesmos para sobreviver. Nessas condições, todos os aspectos básicos foram rapidamente comprometidos.

Na ausência de políticas públicas que facilitassem o acesso a alojamentos adequados, os migrantes dependeram do aluguel privado, colocando o mercado local sob tensão inédita. Entregues a uma especulação imobiliária oportunista, os preços dos aluguéis aumentaram vertiginosamente em um período inferior a três meses, enquanto a qualidade das casas disponíveis foi decrescendo em razão da satura- 
ção do mercado imobiliário. Em pouco tempo, as casas disponíveis eram cada vez mais afastadas do perímetro central da cidade e com menos subsídios básicos (não ofereciam água encanada e/ou eletricidade, banheiro, cozinha). Ainda assim, o valor médio do aluguel ( $\mathrm{R} \$ 500,00$ a $\mathrm{R} \$ 600,00)$ dobrou em relação à situação ordinária ( $R$ \$ 200,00 a $R \$ 250,00$ ). As moradias, em sua maioria, eram alugadas vazias a uma população sem recurso para equipá-las minimamente, passando a funcionar como os acampamentos que os migrantes já haviam vivenciado em seu país de origem após o terremoto: elevada concentração habitacional, refeições coletivas preparadas em fogões a lenha improvisados, banhos ao ar livre, rodízio para dormir em quartos sem colchões...

É fato que muitos tabatinguenses também vivem nesse tipo de moradia e, dessa forma, partilharam objetivamente com os haitianos uma mesma "miséria de condição" (Bourdieu, 1993), sendo esses modos particulares de ocupação coletiva que marcaram uma fronteira de "posição" com a população local. Essa fronteira se materializou em poucas semanas por placas que apareceram pela cidade mencionando "não alugo para haitianos". Os argumentos alegados eram de que eles não possuíam boas condições de higiene, eram barulhentos e/ou estavam em situação de deslocamento frequente, havendo um grande risco de não pagarem o aluguel.

Foi nesse contexto crítico que a "casa dos haitianos" (um motel desativado) surgiu como um paliativo de emergência para os migrantes que chegavam sem nenhum ou pouco recurso. A sala principal, de $50 \mathrm{~m}^{2}$, passou a hospedar 49 pessoas $\left(1 \mathrm{~m}^{2} /\right.$ pessoa) dividindo três colchões cortados em dois, enquanto oito quartos de $10 \mathrm{~m}^{2}$ abrigaram, cada um, de cinco a sete pessoas $\left(1,5 \mathrm{~m}^{2} /\right.$ pessoa). Nesses quartos, cujo valor cobrado era de $\mathrm{R} \$ 100,00^{3}$ cada, mulheres, crianças e casais dormiam coletivamente. Em um total de 118 pessoas, havia apenas um banheiro e um acesso a água não potável para banho, lavagem de roupas, utensílios domésticos e consumo humano.

Nessas condições, agressividade, raiva e forte estresse marcaram regularmente as relações sociais do cotidiano. Brigas surgiram por conta de um colchão, de um objeto pessoal desaparecido ou pelo uso da única rede do quintal.

Logo nas primeiras semanas de "aluguel", a energia elétrica foi cortada, fato atribuído ao não pagamento das faturas (que chegaram a tota- 
lizar R \$ 3.500,00) pelos haitianos. Entretanto, essa dívida não era real, uma vez que remetia, na verdade, aos últimos meses de funcionamento de um motel em falência.

Na casa dos haitianos e em todos os demais pontos de moradia dos migrantes, a água de consumo passou a ser um problema. Após a água local ter sido testada pela vigilância sanitária como não potável, a Prefeitura tomou a medida de fechar dois pontos públicos de acesso apontados como contaminados. O único ponto de abastecimento de água tratada encontrava-se a $5 \mathrm{~km}$ de distância da maioria dos migrantes, os quais dispunham de poucos recursos para se deslocar. Quando, em janeiro de 2012, as unidades de saúde locais passaram a distribuir gratuitamente produtos de tratamento da água, a informação não alcançou os haitianos, confrontados com o obstáculo da língua. O consumo da água contaminada provocou frequentes problemas estomacais e de pele.

De todos os problemas enfrentados, a fome passou a ser o principal. Para a maioria dos migrantes, a única fonte de alimentação eram as refeições distribuídas pela Pastoral da Mobilidade Humana uma vez ao dia durante a semana. "Nos finais de semana, eu carrego meu calvário" resume bem essa situação cíclica de fome, como expressado por um migrante. De fato, a pesquisa quantitativa realizada entre setembro e outubro de 2011 apontou que $85 \%$ dos migrantes declararam comer uma vez ao dia e $83 \%$ declararam sentir fome.

Avaliadas em uma base técnica, as condições de vida da maioria dos migrantes passaram rapidamente a ser aquém das experienciadas pelos migrantes africanos nos centros de retenção de Malta, já denunciadas por MSF como "não humanas"4. De fato, nos meses em que os fluxos migratórios se intensificaram, Tabatinga se configurou como uma "situação humanitária". Entretanto, para as autoridades locais, os migrantes eram sobretudo percebidos como um "risco sanitário".

\section{O Medo Sanitário}

Em um alerta na tribuna da Câmara Municipal de Manaus, um dos vereadores locais, médico de formação, lamentou-se da ausência de controle sanitário para os migrantes haitianos, ressaltando que "a cólera no Haiti é muito intensa, assim como a Aids, e nenhum país pode ajudar outro com o risco de causar doenças em seu próprio povo" ${ }^{\prime \prime}$. Em um artigo posterior ${ }^{6}$, ele mesmo ressaltara que, como no Haiti “não há ser- 
viço público de saúde e, em razão da precariedade da economia, $80 \%$ procuram cuidados de curandeiros tradicionais, que consideram a Aids um feitiço encomendado, e não uma doença transmitida sexualmente. Imagine, então, falarmos de prevenção em um cenário tão desfavorável. Certamente os curandeiros preferem os tambores a uma simples camisinha - por pura, triste e lamentável ignorância" (palavras do vereador/médico de Tabatinga).

Como aponta Noiriel (1988) em sua história da imigração na França, a doença que vem do exterior é um tema recorrente na percepção de todos os movimentos migratórios desde o século XIX. No caso de Tabatinga, a saúde foi sem dúvida o principal cristalizador do medo que os migrantes haitianos inspiraram na população local. O padre da Igreja Católica local ressaltou que, à medida que os haitianos começaram a receber ajuda alimentar de fiéis, o pavor do contato físico se manifestava até nos atos de generosidade, e que por isso as doações diretas aos próprios haitianos eram raras. Ao exemplo do vereador médico citado, essa xenofobia (em seu sentido etimológico: medo do estrangeiro) ganhou certo espaço institucional, alimentando a representação de uma migração incontrolada e perigosa que poderia fazer incorrer em risco sanitário.

Em 2010, testes de HIV foram oferecidos pelos governos municipal e estadual a 300 migrantes e aceitos por 140 deles, sendo revelados quatro casos de HIV positivo $(2,85 \%)^{7}$. A morte, em Manaus, em janeiro de 2012, de um haitiano HIV positivo, amplamente comentada nas mídias locais, deflagrou uma onda de inquietação e preconceito. A Secretaria de Saúde do Estado chegou a solicitar ao governo federal recursos para o reforço na compra de insumos para o diagnóstico e tratamento do HIV e de outras doenças, como cólera, febre amarela e sífilis, consideradas prevalentes no Haiti. Autoridades de saúde chegaram a comentar que, com a chegada dos haitianos, o índice de infecção de HIV entre brasileiros poderia aumentar ${ }^{8}$, despertando o tema da Aids como a doença dos 5H (homossexuais, hemofílicos, haitianos, heroinômanos [usuários de heroína injetável] e hookers [profissionais do sexo]), característica que predominava 30 anos atrás, no princípio da epidemia. Bourdier (2001) tornou público que, na região vizinha da zona de fronteira com a Guiana Francesa, o mesmo tratamento como "agente da doença" foi aplicado ao migrante brasileiro.

O quadro médico estabelecido por MSF para os migrantes haitianos delineou uma realidade bem diferente desse alarmismo sanitário. Tan- 
to as autoridades sanitárias governamentais quanto a equipe de MSF não identificaram nenhum caso de cólera. Em sua maioria, os adoecimentos recorrentes caracterizaram-se como: dermatites (escabioses e micoses), doenças gastrointestinais (diarreias e vômitos), febres sem causa esclarecida, infecções respiratórias, gripes e vaginoses. Esse quadro clínico geral apontou para condições socioeconômicas de vulnerabilidade, mas que não diferiam das condições da população local em geral. Em uma população de 287 migrantes, 12 (4,2\%) relataram algum tipo de adoecimento crônico e/ou agudo ${ }^{9}$. Vale pontuar que uma população recém-chegada e em situação de vulnerabilidade pode ter dificuldades de comunicar seu quadro efetivo de saúde.

Do mesmo modo, a percepção de sua "ilegalidade" pode ter levado os haitianos a evitar o contato com as equipes de saúde, em particular com o hospital militar. Ainda assim, a equipe de MSF que avaliou o estado geral de saúde da população considerou que ela não apresentava um quadro de saúde particular que diferisse da população local. Esse "diagnóstico" coletivo não se mostrou surpreendente, uma vez que se tratava de migrantes recém-enviados por famílias que os haviam elegido beneficiários dos investimentos familiares esperando auxílio financeiro, e, por isso, mandavam indivíduos em boas condições de saúde.

No Canadá, múltiplos estudos mostram que os migrantes, particularmente os recém-chegados, têm condição de saúde globalmente melhor do que a população geral. Esse fenômeno é comumente denominado efeito da boa saúde dos migrantes (Clarkson, Tremblay e Audet, 2002).

Esses dados apontam para a viabilidade de um acompanhamento no nível de saúde pública local, sem acarretar grandes alterações no processo de trabalho das equipes locais. Embora o município de Tabatinga tenha como forma de organização da atenção básica a estratégia de saúde da família, as equipes da atenção básica não realizaram visitas domiciliares até fevereiro de 2012 (quando solicitado e acompanhado por MSF), ainda que os haitianos estivessem dentro das áreas adstritas. A invisibilidade legal, conjugada ao obstáculo linguístico, explica em parte essa falha no sistema de assistência.

\section{Processo Migratório e Saúde Mental}

Considerando a complexidade do contexto haitiano nesses dois últimos anos (conflitos urbanos, miséria, instabilidade política, terremoto, entre outros desastres naturais, lentidão na reconstrução do país, 
epidemia de cólera etc.), o processo migratório se iniciou na interface entre perdas afetivas significativas, trajetórias individuais feitas de acidentes biográficos e desejos de construção pessoal e/ou coletiva.

O investimento feito pelo coletivo familiar potencializa a carga emocional, que muitas vezes torna-se difícil de ser suportada, em particular quando há um grande número de impedimentos legais e econômicos limitando as possibilidades de geração de renda e subsistência. Nessas condições, a saúde mental é um dos indicadores que reflete particularmente o impacto dessa conjunção de elementos na vida dos migrantes.

Ao medir o impacto ${ }^{10}$ desses eventos na saúde mental dos migrantes haitianos, a equipe de MSF encontrou uma situação humanitária baseada em relatos e sofrimentos: maus-tratos sistemáticos e organizados pelo tráfico de pessoas, irresolução administrativa, condições de alojamento desumanas, acesso insuficiente de alimentos, dificuldades financeiras, múltiplas lacunas na assistência e proteção, distorção de imagem no nível da população local, estereótipo e "discriminação cordial" foram os elementos apontados de forma recorrente.

Tal conjunto de dificuldades alimentava nos migrantes, por sua vez, as sensações de culpa e confusão, sentimento de não saber o que fazer, incerteza quanto ao futuro, sentimento de humilhação, vergonha, sensação de invisibilidade e ausência de esperança. Enfim, tal quadro foi ampliado pela fragilidade dos mecanismos de enfrentamento da situação. A busca por empregos (trabalho informal, além de pagamentos irregulares e de baixo valor), as missas e os cultos (em português), as conversas em pares, as leituras e caminhadas e a expectativa de chegar a Manaus e de "ter uma vida melhor" ofereciam poucos paliativos a uma situação subjetivamente percebida como crítica.

É importante apontar que, embora os mecanismos de enfretamento das dificuldades fossem frágeis, não foi identificado, em Tabatinga, nenhum caso de transtorno psiquiátrico (apenas um em Manaus); abuso de álcool e/ou outras substâncias; situação de agressividade e/ou de conflito entre migrantes e/ou entre migrantes e a população local. Isso sugere que os haitianos que chegaram ao Brasil eram bastante resilientes e preparados para as dificuldades encontradas durante um processo migratório complexo e penoso. Em outros termos, as dificuldades enfrentadas não surgiram de uma fraqueza inerente à própria população migrante. 


\section{INVISIBILIDADE POLÍTICA}

A segunda parte deste artigo busca entender como se configurou a situação humanitária de Tabatinga descrita anteriormente. A ideia de "situação" é aqui metodologicamente construída no âmbito da Escola de Manchester (Gluckman, 1958; Mitchell, 1966). O intuito da análise situacional é apreender um conjunto de eventos e ações interconectados a diferentes escalas para possibilitar a compreensão da situação determinada. No caso presente, a descrição das estruturas objetivas e a análise dos diferentes elementos que compõem uma história permitem entender como a situação particular de Tabatinga foi produzida pelo efeito cumulativo de uma série de acontecimentos.

Simetricamente, a situação de Tabatinga deve ser apreendida em sua dimensão performativa, no sentido de que não apenas configurou um "caso" exemplificando ou representando um processo mais abrangente, tendo contribuído para definir tanto local quanto nacionalmente a construção de uma nova questão migratória.

Situando a análise nos níveis local, estadual, federal e internacional, trata-se, ainda, de praticar o que Revel chama de "jogos de escalas" (Revel, 1996), ou seja, fazer variar por hipótese as condições da observação, principalmente a escala ou a focal. O intuito é de restituir a experiência vivida dos haitianos em Tabatinga na pluralidade dos contextos sociopolíticos aos quais ela se encontra presa.

\section{Nível Municipal}

Para as autoridades locais, a chegada dos haitianos configurou um gigantesco hiato, que pode ser resumido no seguinte enunciado: enquanto não recebiam o protocolo como solicitante de refúgio, os haitianos não podiam ser contemplados por nenhum dispositivo de assistência municipal. Um beneficiário não pode ser legalmente invisível. Quando finalmente recebiam o protocolo e podiam então transformar-se em beneficiários, eles deixavam Tabatinga em direção a Manaus em menos de uma semana.

Mas esta situação transitória não foi a única barreira impedindo a assistência pública. A questão do financiamento municipal surgiu logo como uma impossibilidade técnica. A Lei Complementar no 101, de 4 de maio de 2000 (Brasil, 2000), integra o princípio de gestão por projetos amplamente adotados no contexto internacional, assujeitando o or- 
çamento a um plano plurianual definido por diretrizes orçamentárias claras. Nesse contexto, a chegada maciça e inesperada de três mil haitianos a uma prefeitura do tamanho de Tabatinga ultrapassava a margem de flexibilidade dos dispositivos de financiamento: "não existe linha orçamentária para os haitianos" (entrevista com o gestor municipal de saúde) soou como uma justificativa para a não assistência aos migrantes.

A esse argumento somou-se o da escassez de recursos. Como justificar a alocação de verbas para os migrantes haitianos enquanto o município não dispunha de recursos suficientes para despender assistência à saúde e/ou assistência social mesmo para a população tabatinguense, não ofertando nenhuma possibilidade de auxílio a alimentação, moradia e transporte? Nesse contexto, a gestão local invocou o custo político de uma assistência a outrem que não seria entendida e aceita pela população. Manifestou-se também, frequentemente, a preocupação de "não facilitar". Temia-se que qualquer assistência criasse um efeito de oportunidade, acelerando um fluxo migratório já fora de controle.

Finalmente, um último argumento remeteu ao princípio de subsidiariedade: como repetidamente argumentado pela prefeitura, a assistência aos requerentes de asilo deveria ser assegurada pelo governo federal por meio do Conare, responsável pelas questões que envolvem o processo migratório. Em termos legais, o município não teria competência para prover assistência.

Uma atenção mais específica à saúde funciona como um analisador pertinente dessas barreiras. Na ausência de uma política explícita de gestão da população migrante, os profissionais de saúde ficaram com pouca margem de adaptação e ação. Muitos mencionaram as limitações em termos de comunicação, dificultando e/ou impedindo o atendimento, ainda que organizações não governamentais (MSF e Igreja Católica) se propusessem a auxiliar na elaboração de materiais impressos e de formações para os trabalhadores da assistência que facilitassem os atendimentos no nível da atenção primária.

Mesmo sendo oferecida formação técnica gratuita para o atendimento às reações e aos adoecimentos recorrentes com populações em situação de migração, bem como material para comunicação (em ambas as línguas: português e crioulo), a gestão municipal não repassou a informação para seus técnicos e não facilitou a liberação desses trabalhadores das unidades de saúde onde estavam para a participação na formação, 
acarretando o esvaziamento dos espaços de formação. O discurso predominante nas estruturas locais de saúde foi diplomático e cordial; contudo, baseou-se na ausência de uma articulação política e técnica clara com os haitianos, os quais acabaram por ficar de fora dos dispositivos existentes de assistência.

Resultou dessa situação o paradoxo de que, na escala local na qual os migrantes estavam fisicamente presentes, sua situação estava legal e politicamente invisível aos olhos do poder da região.

\section{Nível Estadual}

O município de Tabatinga dista $1.200 \mathrm{~km}$ da capital do Estado do Amazonas, em uma área rodeada pela maior floresta do mundo - Amazônia - e sem acesso por via terrestre. A pequena cidade sofre por sua própria situação periférica. Soma-se a essa particularidade o fato de que o Estado do Amazonas não possui órgãos governamentais que tratem da gestão de fluxos migratórios e / ou de tratamento legal dos requerentes de asilo, aumentando ainda mais a lacuna entre a situação local e o nível federal no qual esta podia ser de fato abordada.

Salienta-se que o estado e o município poderiam ter estabelecido uma interface com o poder federal na construção política da questão e de suas dimensões emergenciais e humanitárias. A ajuda estatal versou sobre o transporte dos haitianos de Tabatinga a Manaus e a alimentação apenas nas últimas semanas do processo migratório. Os barcos oriundos de Tabatinga começaram a trazer até Manaus os contingentes de migrantes protocolizados. Tanto na praça central quanto nos bairros periféricos, os haitianos estavam se tornando visíveis, não apenas por seu fenótipo distinto da população manauara, mas pelas notícias cotidianas anunciadas pela mídia municipal.

As notícias diárias anunciavam as dificuldades de alojamento, alimentação, acesso ao mercado de trabalho, entre outras necessidades dos migrantes. Por esses e outros motivos (medo sanitário, de fluxos incontrolados, de perder espaço no mercado de trabalho para estrangeiros...), "os haitianos" estavam de fato se configurando como uma "questão social" para a população de Manaus.

Ainda assim, os haitianos bloqueados em Tabatinga permaneceram em uma ampla invisibilidade política. Quando o assunto foi discutido na Assembleia Legislativa do Estado, constituiu-se dentro de uma re- 
tórica sanitarista, fazendo dos haitianos um grupo de risco. Sob solicitação oficial do Ministério da Saúde, o estado elaborou, em fevereiro de 2011, um diagnóstico da saúde da população haitiana, a fim de evitar a proliferação do cólera no país. A visita técnica foi encerrada sem que fossem propostas soluções e / ou auxílio à população de migrantes.

Apenas um deputado estadual, também membro ativo da Igreja Católica, tentou sem sucesso, durante meses, levantar a questão para ambos os Poderes Legislativo e Executivo estadual e federal. Ele denunciou que, em Tabatinga, os haitianos viviam "em condições precárias e quase subumanas, um verdadeiro aglomerado de pessoas". Alertou para "a situação dos haitianos, já que está se tornando insustentável por parte da Igreja, pois, após eles serem legalizados pela Polícia Federal, acabam migrando para Manaus"; mas, como ele próprio resumiu: "ninguém quer se envolver, porque pode criar um efeito bola de neve" (entrevista com deputado estadual, que pediu anonimato).

Como resultado das inúmeras tentativas, o governo do Estado, por meio da Secretaria de Assistência Social, orçou uma verba de R \$350.000,00 (dos $\mathrm{R} \$ 700.000,00$ solicitados ao governo federal), mas parte desse recurso chegou apenas em benefício da última leva de migrantes.

Finalmente, o estado não se constituiu em uma testemunha privilegiada perante as autoridades federais. Deixamos a análise para a conclusão deste texto. Por enquanto, vale mencionar que as fronteiras legais entre as competências territoriais nos níveis municipais e estaduais e sua articulação dificultaram um tratamento "holista" da população haitiana de Tabatinga e sua construção como "sujeito" com necessidades assistenciais.

O evento de Tabatinga surge dentro de determinada "estrutura" institucional que não estava preparada. Sem dúvida, a irresolução normativa sobre o status legal dos migrantes também dificultou a qualificação política de sua situação.

Supõe-se que, no plano estadual, a situação de Tabatinga tenha sido mantida em relativa confidencialidade, talvez porque tenha sido apreendida pelos atores locais como um risco político. Um risco perante uma significativa parte da população do estado, que não necessariamente interpretaria como "generosidade" uma política de assistência a estrangeiros em um contexto altamente competitivo pela alocação dos recursos. Um risco perante o poder federal, na ausência de uma 
qualificação clara do significado político e diplomático a ser atribuído à chegada dos haitianos ao solo brasileiro.

Nesse contexto, a distância geográfica de Tabatinga tornou-se, de certa forma, conveniente. Funcionou como uma medida de contenção de uma população inesperada e do problema político por ela acarretado. Essa hipótese permitiria entender como, durante mais de um ano, a situação de Tabatinga não alcançou a visibilidade política para que pudesse se construir em um "evento crítico"11 e ser efetivamente resolvida.

\section{A Polícia Federal}

Em Tabatinga, a Polícia Federal foi o principal ator responsável pelo processamento dos requerentes de asilo, controlando a entrada e a saída de pessoas nas fronteiras nacionais. Nos últimos anos, sua função limitou-se a processar os poucos e esporádicos pedidos ainda oriundos de uma Colômbia em vias de pacificação. A chegada dos haitianos colocou sob tensão extrema o posto de fronteira, que se encontrou de repente na primeira linha de gerenciamento de um fluxo migratório inesperado.

Ressalta-se que os haitianos entraram como requerentes de asilo. Em seu artigo 9o a Lei de Refúgio (Brasil, 1997) estipula que: "A autoridade a quem for apresentada a solicitação deverá ouvir o interessado e preparar termo de declaração, que deverá conter as circunstâncias relativas à entrada no Brasil e às razões que o fizeram deixar o país de origem" (s.p.).

Em outros termos, coube à Polícia Federal de Tabatinga "ouvir" as centenas de "interessados" na forma de entrevistas individuais, por meio das quais os até então migrantes ilegais podiam transformar-se em requerentes de asilo e receber um protocolo temporário, que liberava, por sua vez, o embarque de Tabatinga para Manaus. Em termos práticos, dadas as condições locais de recurso da Polícia Federal, a espera para a entrevista passou a ser, em média, de três meses.

Toda a situação de Tabatinga transcorreu dentro dessa perspectiva. Nesse sentido, parte dos migrantes haitianos encontrou-se por três ou quatro meses em situação humanitária crítica, pelo fato de a Polícia Federal de Tabatinga não possuir condições operacionais para conduzir as entrevistas em prazo menor. 
Estabeleceu-se que a capacidade de atendimento do posto seria de 24 entrevistas por semana, divididas em pares de oito, três dias por semana. Nesse mesmo período, o fluxo de entrada era de 100 a 150 novos migrantes por semana. O contingente de migrantes em Tabatinga aumentou, assim como o tempo de espera. Por sua vez, as condições de vida e de subsistência pioraram com a saturação dos recursos e da solidariedade local. A lógica era aritmética.

Uma rotina de crise se estabeleceu. A Polícia Federal acabou terceirizando a manutenção da lista de espera à Pastoral da Mobilidade Humana, único ator que provera assistência aos migrantes em caráter emergencial. A justificativa versava sobre o fato de que os migrantes tentavam negociar com os policiais uma posição mais "vantajosa" na lista.

A fim de solucionar parte dessa problemática, a Pastoral da Mobilidade Humana passara a receber os passaportes por ordem de chegada, estabelecendo uma lista que semanalmente era publicada nos muros da pastoral, sendo, na sequência, os passaportes entregues à Polícia. Esta solicitava repetidamente ajuda ao Estado, a fim de realizar todas as entrevistas em um período menor de tempo. Por duas vezes, foi possível organizar "mutirões" com reforços de Manaus, que permitiram realizar 300 entrevistas por semana.

Em seu cotidiano, os policiais estavam vivendo o Mito de Sísifo, tal como narrado por Albert Camus (1989) em sua reflexão sobre o absurdo. Eles sabiam que os migrantes não seriam reconhecidos como refugiados, porque a informação já havia sido comunicada pelo centro da gestão governamental. Ainda assim, tinham de realizar as entrevistas dentro da Lei de Refúgio. Ou seja, dispunham-se a operar uma ficção jurídica custosa, ainda que no Itamaraty a decisão já tivesse sido tomada.

Então, como aponta Camus (1989), diante do absurdo, a revolta foi a única opção. Revolta ao manifestar sua incompreensão: "não são refugiados, mas são recebidos como tais"; "os haitianos estão em um vazio jurídico, nem ilegais nem legais" (entrevista com migrante haitiano). Revolta perante os próprios haitianos, que "manipulam a categoria de refugiados". Policiais admitiram, assim, ter perdido a paciência nas entrevistas diante de argumentos como "sou requerente de asilo porque gosto do Brasil" ou "sou fã da seleção brasileira de futebol". Revolta, enfim, perante o que percebiam como a passividade dos políticos em face de uma invasão maciça. 
Parte dos atores locais acreditava que prover um tratamento administrativo veloz iria "chamar muito mais gente". Somava-se a este o receio de que as condições de vida difíceis fossem facilitar "amizades com o narcotráfico": "o Brasil já não consegue cuidar de seus [criminosos] e tem que cuidar dos de outros", conforme palavras de autoridades locais.

Como principal ator do governo federal em contato direto com os migrantes, os policiais de Tabatinga viviam muito concretamente as consequências da irresolução legal e política sobre o assunto dos migrantes haitianos. Tinham consciência de que a situação de Tabatinga era diretamente provocada pela lista de espera para a entrevista que eles próprios realizavam. Sabiam que necessitavam aumentar o contingente de policiais para solucionar um problema, afetando tanto os migrantes quanto a cidade inteira. Mas, na ausência de visibilidade e de uma política migratória clara, também sabiam que permaneceriam condenados ao absurdo: "a solução está em Brasília".

\section{O Conare}

O Brasil assinou, em 1960, a Convenção de $1951^{12}$ das Nações Unidas definindo o Estatuto de Refugiado dentro de uma dupla reserva, circunscrevendo-o ao contexto particular da Segunda Guerra Mundial: reserva geográfica (a convenção somente se aplica a refugiados oriundos da Europa) e reserva temporal (refere-se a acontecimentos ocorridos antes de 1o de janeiro de 1951). É somente no contexto da redemocratização que o Brasil começa a levantar essas reservas e receber pequenos contingentes oriundos do Irã e de Angola. Na época, mesmo os vizinhos, chilenos e argentinos fugindo de regimes ditatoriais, somente conseguiram entrar no Brasil como "estrangeiros temporários", e não como refugiados.

Aderindo à Declaração de Cartagena (OEA, 1994), o Brasil finalmente abre mão, em 1989, da reserva geográfica por meio do Decreto no 98.602 e torna-se livre para receber refugiados independentemente da origem. Mas é somente em 1997 que uma lei específica é promulgada (Lei no 9.474). Ela define o mecanismo para a implementação do Estatuto de Refugiados e cria o Conare.

Segundo Luiz Barreto (2010), ex-presidente do Conare, a lei foi, então, considerada "pela própria ONU como uma das leis mais modernas, mais abrangentes e mais generosas do mundo". Sua originalidade con- 
siste notavelmente na composição tripartite do Conare: governo, sociedade civil e Nações Unidas. A diplomacia brasileira ainda ganhou destaque por sua participação, em 2004, na implementação de um Plano de Ação para Fortalecer a Proteção Internacional dos Refugiados na América Latina e por ter promovido a tese de que "assuntos migratórios sejam tratados de maneira absolutamente vinculada aos direitos humanos" (Barreto, 2010).

Entre 1997 e julho de 2010 (quando se iniciou o fluxo migratório dos haitianos), o Brasil havia recebido um total de 4.306 refugiados, principalmente de países como Angola e Colômbia. Em comparação a números brutos, somente no ano de 2011, o Paquistão recebeu 1.702.700 refugiados, a Alemanha, 571.500, e os EUA, $264.800^{13}$. Conforme sugere Barreto (2010:21), o que esses dados apontam é que a lei brasileira "é ainda pouco conhecida na sociedade, é pouco conhecida dos operadores do direito, é pouco conhecida, enfim, até dos meios acadêmicos". Nesse contexto, ao solicitar o Estatuto de Refugiados, os 3.500 haitianos constituiriam, a princípio, um desafio para a aplicabilidade de suas intenções e disposições.

O artigo 7으 do Título II da Lei no 9.474 estipula que "o estrangeiro que chegar ao território nacional poderá expressar sua vontade de solicitar reconhecimento como refugiado a qualquer autoridade migratória que se encontre na fronteira". No contexto das leis migratórias restritivas vigentes no país, como veremos em seguida, entrar como solicitante de refúgio era de fato o único caminho legal que os haitianos poderiam seguir. No entanto, o artigo 1ㅇdefine que será reconhecido como refugiado todo indivíduo que, "devido a fundados temores de perseguição por motivos de raça, religião, nacionalidade, grupo social ou opiniões políticas encontre-se fora de seu país de nacionalidade" (s.p). Nessa base e sob a orientação do Acnur, foi determinado que os haitianos não poderiam ser reconhecidos como refugiados porque sua situação não correspondia a nenhum dos critérios da lei. Afinal, nem o medo sísmico, nem o surto de cólera, nem a extrema precariedade econômica fundamentavam um "temor" tal como definido pela lei. Logo, a situação configurou-se como um gigantesco hiato: requerentes do estatuto de refúgio para entrar legalmente no Brasil, os haitianos não poderiam permanecer como refugiados. Sua visibilidade, do ponto de vista legal, tinha prazo marcado: a data de expiração do protocolo temporário. 
Ainda assim, até a decisão final e estritamente individual do Conare, os migrantes eram oficialmente requerentes do Estatuto de Refugiados e deveriam ter sido tratados como tais. Ou seja, poderiam beneficiar-se das medidas de assistência e proteção garantidas pelas leis e convenções internacionais. No entanto, esse não fora o caso desses migrantes. Enquanto havia condições legais para uma cooperação direta com o município e o estado, o Conare antecipou, de certa forma, o indeferimento dos pedidos como justificativa da não implementação dos dispositivos assistenciais. Por exemplo, no procedimento padrão, os migrantes deveriam proceder a uma segunda entrevista, mas, no caso dos haitianos, recomendou-se não fazê-lo, configurando-se como uma violação dos direitos garantidos na legislação.

A gestão tripartite do Comitê, inicialmente pensada como virtude política e instrumento de boa governança, potencializou uma desresponsabilização do poder público: o dever de assistência foi sistematicamente terceirizado à sociedade civil (Caritas, Pastoral do Migrante) sem coordenação e meios adequados.

Dois elementos podem explicar parte dessa situação. O primeiro versa sobre a dificuldade de obter uma visão clara, por parte do Poder Executivo, do estatuto político dos haitianos nos contextos nacional e internacional. Não podendo se configurar como refugiados, então o que seriam? Haveria uma medida humanitária "generosa" que viria aliviar o complexo processo legal? O que aconteceria uma vez que fossem indeferidos como refugiados? O status internacional pós-terremoto dos haitianos permitiria sua extradição?

O segundo elemento diz respeito ao próprio momento político do Conare na condição de instituição. Em 2010, sua decisão de não reconhecer o Estatuto de Refugiado político e de extraditar o italiano Cesare Battisti ${ }^{14}$ foi ignorada, e o caso, transferido ao Supremo Tribunal Federal, que acabou deferindo o pedido do ex-ativista italiano. À frente desse caso, o Comitê ganhou visibilidade política, polarizando a insatisfação dos parlamentares dos dois lados (pró e contra a extradição de Battisti). Como resultado, em 2011, cerca de 20 processos tramitaram no Congresso para modificar ou até suprimir a lei brasileira de refugiado e/ou redefinir as atribuições do Comitê. Consequentemente, o Conare ficou politicamente fragilizado na tomada de decisões que diziam respeito aos migrantes haitianos. Possivelmente, a discrição foi uma das consequências desse processo. 
Adotando uma postura de confidencialidade, o Conare antecipou o indeferimento dos pedidos antes do fim de sua tramitação legal, transferindo-os para o CNIG, que, em "condições especiais", pode conceder a permanência para não refugiados.

\section{CNIG}

A posição do CNIG somou-se ao hiato no qual se transformou a situação de Tabatinga. Resumindo, os haitianos não eram refugiados, mas podiam entrar no Brasil como requerentes. Eles eram migrantes, mas não podiam entrar no Brasil como tais. $\mathrm{O}$ motivo foi apontado em relatório do Acnur, o qual denotara que a lei de migração nacional é ultrapassada e restritiva, o que resulta em migrantes usando o processo de asilo em uma tentativa de legalizar a sua permanência no Brasil. No entanto, foi pela lei estabelecida na Resolução Normativa no 27, de 25 de novembro de 1998, que alguns haitianos acabaram por conseguir a permanência. A resolução estipula, em seu artigo 1ํ, que "serão submetidas [sic] ao Conselho Nacional de Imigração as situações especiais e os casos omissos, a partir de análise individual". Nessa base, o Conare passara a transferir os pedidos para o CNIG, com o intuito de transformar, na medida do possível, os "não refugiados" em migrantes em "situações especiais".

A transferência de centenas de casos constituiu por si só uma situação especial para o próprio CNIG, que acabou criando um grupo específico de conselheiros após ter "separado os haitianos" das demais solicitações. Passou-se a analisar sequencialmente os casos que teriam relação direta com o terremoto desde janeiro de 2010. Assim, essa é a base em que foi resolvida a aplicação da resolução normativa referente à atribuição da permanência por "motivos humanitários". Porém, tal critério provou ser de difícil avaliação: as entrevistas tinham sido realizadas dentro dos critérios da Lei de Refúgio, e não com o intuito de estabelecer uma relação direta ou não com o terremoto. Por sua parte, os próprios migrantes não tinham sido informados do critério, de tal modo que não especificavam espontaneamente de que forma tinham sido afetados.

Ainda, em desconformidade com a Lei de Refúgio, as entrevistas foram realizadas sem tradutores profissionais, e muitas informações não foram formalizadas. O critério, sobretudo, estabelecia um corte, impedindo a avaliação de situações individuais "especiais" em outra base, 
pois um terço dos migrantes não vivia no Haiti no momento do terremoto. Enfim, como apontou um assessor governamental, "a distância do terremoto está ficando grande": na medida em que o fluxo migratório aumentava, até quando o argumento seria justificável?

O CNIG autorizou a permanência no Brasil de 199 haitianos em março de 2011, de 237 em junho do mesmo ano e de 354 em setembro de 2012. Em outubro de 2011, um conselheiro reconheceu que "uma luz amarela" estava acesa: "Se continuarmos, abriremos portas para outros países. E a África?" A falta de uma determinação política clara potencializou a dificuldade de suportar uma resolução. Sem indeferir, o CNIG passou a pedir complementos individuais de informação pelo viés do Conare, ciente de que tais pedidos dificilmente chegariam a uma população em situação de trânsito sem resolução.

\section{ACNUR}

O Acnur foi criado pela Assembleia Geral da Organização das Nações Unidas (ONU) em 14 de dezembro de 1950 para "proteger e assistir às vítimas de perseguição, da violência e da intolerância"15. No Brasil, o trabalho do Acnur é pautado pelos mesmos princípios e funções que em qualquer outro país: proteger os refugiados e promover soluções duradouras para seus problemas. Como mencionado anteriormente, a agência atua em cooperação com o Conare com representação permanente. A princípio, como requerentes de refúgio à espera de uma decisão individual final, os haitianos deveriam ter-se beneficiado da rede de assistência estabelecida no Brasil pelo Acnur, mas, antecipando o indeferimento legal, ou seja, que eles não seriam reconhecidos como refugiados, não foi esse o procedimento utilizado para os quase 4 mil migrantes. $\mathrm{O}$ Acnur não disponibilizou aos requerentes os direitos previstos para aqueles em situação de refúgio: duas noites de hotel, assistência social e financeira de até $\mathrm{R} \$ 300,00$ durante três a seis meses.

Como membro do Conare, o Acnur apontara para o fato de que os haitianos requerentes de asilo não possuíam pré-requisitos básicos para serem considerados refugiados. Essa orientação foi determinante no processo de operacionalização do status dos haitianos, dando legitimidade a decisões que estimularam a não assistência: "a ONU diz que não são...". Entretanto, o Acnur fizera um trabalho de advocacia, recomendando a não deportação dos haitianos, e, nesse sentido, mobilizou para que uma solução "humanitária" fosse encontrada. 
Ressalta-se aqui o fato de esses migrantes serem considerados, em caráter coletivo, "não refugiados" anteriormente a um parecer individual. Apesar de ter um bom conhecimento da situação local (o Acnur mantém em Manaus sua única representação no Brasil fora de Brasília), o escritório encontrou-se incapacitado de tomar decisões. Nesse sentido, dois elementos requereram objetivamente sua atenção e atuação.

O primeiro diz respeito ao tratamento coletivo de situações legalmente individuais, embora tendo consciência de que um dos grandes dificultadores dos movimentos migratórios contemporâneos está no caráter "misto" dos fluxos, ou seja, na medida em que reúne migrantes econômicos, deslocados e refugiados. Com relação aos haitianos, embora a grande maioria se encaixasse de fato na primeira categoria, alguns casos remetiam a situações que poderiam se enquadrar na Lei de Refúgio brasileira. Como exemplo, pode-se citar o relato de um homem ameaçado por sua militância política junto a uma candidata opositora às gangues de Porto Príncipe nas últimas eleições presidenciais (2010-2011). Esse caso foi detectado pelo CNIG (e não pelo Conare). Assim, questiona-se aqui o número de exemplos como esse que permaneceram na invisibilidade em razão das condições nas quais os requerentes foram entrevistados e administrativamente processados.

O segundo elemento diz respeito ao tráfico internacional de seres humanos, o qual é um dos critérios de demanda de proteção internacional. A clandestinidade frequentemente implica o tráfico de seres humanos, sendo esse o caso de parte dos haitianos que chegaram a Tabatinga. O Acnur recomenda, baseado na convenção de 1951, que necessidades potenciais de proteção de pessoas que foram traficadas ou estão em risco de serem traficadas devem ser levadas em consideração a fim de serem protegidas. No entanto, essa prerrogativa não se aplicou ao pedido dos haitianos, ainda que fosse notório que sua grande vulnerabilidade tivesse sido acentuada pela atuação dos coiotes.

Parte dessa conjuntura explica-se pelo cenário geopolítico internacional tenso (Afeganistão, Sudão, República Democrática do Congo, Líbia...), sendo o Brasil percebido como "indo muito bem" e isento da problemática dos refugiados. Por esse motivo, o Acnur do Brasil padece de uma dotação orçamentária reduzida, incapacitando qualquer medida da escala que a situação dos haitianos requer. Em outros ter- 
mos, a invisibilidade dos haitianos refletia parte da invisibilidade do Acnur do Brasil em âmbito internacional.

\section{O Poder Executivo e a Política Externa}

No contexto geopolítico de 2010-2011, a migração haitiana conformou, para o Brasil, uma situação diplomática delicada. No momento da definição do status dos migrantes haitianos, o Brasil apresentava sua candidatura ao Conselho de Segurança da ONU. Um forte apelo fora dado à implicação do país na ajuda à regulamentação internacional dos direitos humanos, com o exemplo da participação decisiva do Brasil na coordenação da Missão das Nações Unidas para a estabilização no Haiti (Minustha). Isto é, o Haiti, nesse sentido, apresentara-se como uma vitrine do savoir-faire (saber-fazer) brasileiro, e por isso denotava importância estratégica. Nesse contexto, deportar maciçamente migrantes haitianos seria fechar fronteiras para uma solução politicamente insustentável. De outro lado, na ausência de um acordo subcontinental acerca das migrações haitianas, e como as fronteiras dos países tradicionais de migração estavam se fechando, o Brasil não podia por si só assumir uma postura de "generosidade" sem correr o risco de estimular fluxos que seriam politicamente custosos em nível nacional. Em outros termos, o hiato sentido nos âmbitos municipal e estadual e dentro dos próprios órgãos federais refletia a questão "ontológica" da diplomacia brasileira. De certo modo, também para o Executivo a situação de Tabatinga fora "funcional", no sentido de que funcionava como uma zona hermética, permitindo manter a distância entre o problema e sua solução e amortecendo custos políticos.

\section{O Desfecho: Uma Reabertura da Questão Migratória}

Em janeiro de 2012, passados dois anos do início das migrações haitianas na Amazônia e com a já consolidada situação humanitária em Tabatinga, essa irresolução política já não era mais possível. Entretanto, o caso dos haitianos tinha ganhado notoriedade midiática e, em novembro de 2011, alcançado o estágio de "questão nacional".

Em Brasileia, pequena cidade localizada na fronteira do Acre com o Peru, onde haitianos também passaram a chegar, estruturou-se uma melhor articulação com o governo federal, facilitando a politização da questão. A implementação - altamente simbólica - de um projeto de assistência da organização não governamental dos MSF em Tabatinga 
também pode ter contribuído para uma maior conscientização do problema.

Nesse período de dois anos, fora decidido que os haitianos que estavam em solo brasileiro seriam excepcionalmente regularizados. Em contrapartida, novos migrantes seriam impedidos de entrar no Brasil como requerentes de refúgio. Considerados ilegais, poderiam ser deportados. Uma cota de 100 vistos mensais por dois anos seria, entretanto, concedida a requerentes a partir do solo haitiano.

Rapidamente, porém, o dispositivo mostrou suas insuficiências para conter o fluxo e as regularizações por motivos humanitários se aceleraram, chegando a 13.669 em 2013 (fonte: Ministério da Justiça). Logicamente, em abril de 2013, o CNIG determinava o fim do limite de 1.200 vistos anuais e devolvia a "questão haitiana" para uma reforma em profundidade da Política Nacional de Migração.

\section{CONSIDERAÇÕES FINAIS}

A chegada dos haitianos à cidade de Tabatinga constitui um evento crítico na história migratória brasileira: a entrada do Brasil nas rotas migratórias globalizadas. Tal evento confirma a atratividade do país no novo cenário geopolítico do século XXI. Revela também que, desde a implementação das cotas migratórias na década de 1930, os tempos mudaram: a globalização dos fluxos de comunicação e o transporte tornam consideravelmente complexo o controle dos fluxos migratórios.

Porém, como demonstrado neste artigo, a situação de Tabatinga perdurou justamente porque não alcançou a visibilidade necessária para ser reconhecida como um evento crítico. Nem refugiados nem migrantes, os haitianos sofreram por sua posição intersticial entre uma Lei de Refúgio moderna, mas inaplicável a amplos movimentos coletivos, e uma lei de migração "ultrapassada e restritiva". Essa indeterminação legal estava atrelada a uma complexa invisibilidade política. Nos planos locais, estaduais ou federais, a chegada dos haitianos surgiu como um fato singular, atrapalhando os mecanismos orçamentários e de governança, desafiando os dispositivos de assistênciae trazendo questões inconfortáveis sobre a oportunidade política de "cuidar dos outros" em um contexto de competição generalizada pelos recursos do Estado. Por esses motivos, Tabatinga funcionou tacitamente como espaço de contenção. 
Mas a irresolução também foi antropológica. Como qualquer momento de "primeiro contato", a chegada dos haitianos deslocava a fronteira da alteridade e da identidade. No contexto amazonense, em que a diferença étnica e cultural tornou-se uma via importante de acesso a direitos fundamentais, a aparição dessas "alteridades radicais" ameaçava perturbar as fronteiras - tênues - das alteridades locais.

No Brasil voluntariamente multiculturalista do século XXI, que promove as "diferenças" e a "diversidade" no seio de uma população de cidadãos desiguais, mas fortemente integrados à comunidade nacional, a chegada dos haitianos reavivou a pergunta sempre angustiada do "nós". Contudo, logo essa pergunta se encontrou agitada pelo vivo imaginário humanitário de um contexto ainda marcado pelas imagens do terremoto. De vítimas a transmissores de HIV, de invasores a sujeitos da solidariedade internacional, os haitianos passaram por transfigurações múltiplas que também contribuíram para a indeterminação de sua situação. Quantos movimentos espontâneos de assistência esboçados em nome da solidariedade foram abortados por receio do contato?

Rompendo com essa hesitação, foi finalmente com base nos argumentos da generosidade e da compaixão que o Poder Executivo enfrentou a situação apresentada. Aos haitianos que já estavam em solo brasileiro, vistos especiais foram ofertados por razões humanitárias. Aos que ainda poderiam vir ao Brasil uma cota de 100 vistos mensais foi ofertada. Segundo o Itamaraty, a medida teve o intuito tanto de limitar a "fuga de cérebros" do Haiti de pessoas importantes para reconstruir o país quanto de não alimentar uma rota criminosa, a qual poderia estimular a ilicitude das migrações, como o tráfico de pessoas e casos de trabalhadores escravos. A supressão desta política de cotas em 2013 mostrou os limites e os artifícios do argumento da generosidade e seu regime de exceção perante a realidade dos fluxos migratórios globalizados.

A respeito desse ponto, Fassin (apud Vidal, 2011) denomina "governo humanitário" um poder que tira sua força do lugar central das emoções na definição das políticas destinadas a aliviar o sofrimento de outrem em nome da experiência da compaixão. Porque essa lógica de "governo humanitário" mantém a distância e entretém uma relação permanente de desigualdade, Fassin faz dela a parte sombria das democracias modernas. No mesmo registro argumentativo, Boltanski 
(1993) aponta, em seu livro sobre o "sofrimento à distância", que "a política da piedade", que somente reconhece pessoas nas dimensões da felicidade ou da infelicidade, faz obstáculo a uma verdadeira "política da justiça".

Aplicado à situação de Tabatinga, esse debate geral aponta para a evidência de que a generosidade invocada de vistos humanitários e de cotas restritivas não substitui o que deveria ser uma consistente política migratória. Da mesma maneira, na ausência da compreensão e da análise de múltiplos níveis políticos de gestão das falhas de assistência e proteção, outras situações análogas à de Tabatinga poderão vir. $\mathrm{O}$ evento crítico de Tabatinga, mesmo sendo pouco reconhecido como tal, ainda pode fornecer a ocasião ímpar de transformar a singularidade de sua erupção na exemplaridade de uma resposta e tratamento político global.

(Recebido para publicação em março de 2013)

(Reapresentado em novembro de 2013)

(Aprovado para publicação em junho de 2014) 


\section{NOTAS}

1. Frédéric Vandenberghe (IESP/UERJ) participou da primeira fase da pesquisa em Tabatinga. Agradecemos muito por sua valiosa contribuição à coleta de dados e análise.

2. Disponível em <http://oglobo.globo.com/pais/acre-sofre-com-invasao-de-imigrantes-do-haiti-3549381>.

3. No último mês do fluxo migratório, a Igreja Católica responsabilizou-se pelos aluguéis daqueles que não eram capazes de fazê-lo por sua própria conta. Uma compensação financeira pelo Estado do Amazonas foi negociada.

4. Disponível em <http://www.aerzte-ohne-grenzen.at/fileadmin/data/pdf/reports/2009/MSF_Report_Malta_2009.pdf.

5. Disponível em <http://www.blogmarcossantos.com.br/2012/02/08/homerode-miranda-leao-medico-e-vereador-alerta-riscos-de-colera-em-haitianos/>.

6. Disponível em <http://www.blogdafloresta.com.br/o-grito-da-saude/9588-haitianos-controle-sanitario-de-fronteira-homero-de-miranda-leao-.html>.

7. MSF, que não participou dessa operação, lembra que, ao aplicar os testes, é necessário que se tenha um conjunto de ações (deteç̧ão, orientação, tratamento, acompanhamento), o que não foi o caso, segundo relatos da população testada.

8. Disponível em <http://www.agenciaaids.com.br/noticias/interna.php? id $=18464>$.

9. Dados obtidos por meio da Ficha A, preenchida pelos agentes comunitários de saúde brasileiros em colaboração com haitianos voluntários.

10. Foram utilizados instrumentos qualitativos, como: escuta ativa, visita domiciliar, grupos focais, role-play, desenhos e entrevistas individuais.

11. Restrita à situação de Tabatinga, a análise não dá conta da maneira com que a assistência acabou se organizando para os haitianos que chegaram a Manaus a partir de março de 2011, quando foi criada uma Comissão de Apoio aos Haitianos pelo governo do Estado, reunindo várias secretarias e organizações da sociedade civil.

12. Disponível em http://www.acnur.org/t3/portugues/informacao-geral/o-que-e-a-convencao-de-1951/

13. Disponível em <http://www.unhcr.fr/501145f39.html>.

14. Ativista dos Camisas-Vermelhas, Battisti foi acusado do assassinato de quatro pessoas na década de 1970 e recebeu pena de prisão perpétua na Itália. Escapou em 1981, refugiou-se no México e, em seguida, na França. Após a decisão da França, em 1994, de extraditá-lo para a Itália, ele fugiu para o Brasil. Preso em 1997, cumpriu quatro anos de prisão no Brasil beneficiando-se, finalmente, de uma decisão de não extradição. Assumida no último dia do mandato do presidente Lula, em 31/12/2010, após debates tensos no Supremo Tribunal Federal, a decisão provocou uma tensão diplomática com a Itália.

15. Disponível em <http://www.acnur.org/t3/portugues/informacao-geral/breve-historico-do-acnur/ $>$. 


\section{REFERÊNCIAS BIBLIOGRÁFICAS}

BAENINGER, Rosana (org.). (2012), Imigração Boliviana no Brasil. Campinas, Núcleo de Estudos de População-Nepo/Unicamp.

BARRETO, Luiz (org.). (2010), Refúgio no Brasil: A Proteção Brasileira aos Refugiados e seu Impacto nas Américas, Brasil. Ministério da Justiça. Brasília, ACNUR, Ministério da Justiça. Disponível em http://www.migrante.org.br/migrante/images/arquivos/refugio-no-brasil.pdf. Acesso em 1/5/2014.

BOLTANSKI, Luc. (1993), La Souffrance à Distance: Morale Humanitaire, Médias et Politique. Paris, Métailié.

BOURDIER, Fréderic. (2001), “Trajectoires Sociales entre l'Amazonie Française et Brésilienne des Personnes Contaminées par le VIH". Migration et Santé, no 104, pp. 79-90.

BOURDIEU, Pierre. (1993), La Misère du Monde. Paris, Seuil.

BRASIL. (1997), Lei no 9.474, de 22 de julho de 1997. Disponível em http:/ / www.planalto.gov.br/ccivil_03/Leis/L9474.htm. Acesso em 1/4/2014.

. (2000), Lei Complementar no 101, de 4 de maio de 2000. Estabelece normas de finanças públicas voltadas para a responsabilidade na gestão fiscal e dá outras providências. Disponível em http:/ /www.planalto.gov.br/ccivil_03/leis/LCP/_Lcp101. $\mathrm{htm}$. Acesso em 8/4/2014.

CAMUS, Albert. (1989), O Mito de Sísifo: Ensaio sobre o Absurdo. Rio de Janeiro, Guanabara.

CLARKSON, May; TREMBLAY, Rébecca e AUDET, Nathalie. (2002), Santé et Bien-être, Immigrants Récents au Québec: Une Adaptation Réciproque? Rapport de l'Étude auprès des Communautés Culturelles 1998-1999. Québec, Institut de la Statistique du Québec.

DAS, Veena. (1995), Critical Events: An Anthropological Perspective on Contemporary India. Nova Délhi, Oxford University Press.

ESTERCI, Neide e FIGUEIRA, Ricardo. (2007), “Trabalho Escravo no Brasil: As Lutas contra Condutas Patronais Escravagistas". Em Pauta, vol. 20, pp. 85-98.

FASSIN, Didier. (2010), La Raison Humanitaire: Une Histoire Morale du Temps Présent. Paris, Éditions de l’EHESS/Le Seuil/Gallimard.

FRY, Peter e VOGT, Carlos. (1996), Cafundó, a África no Brasil: Linguagem e Sociedade. São Paulo, Companhia das Letras.

FURET, François. (1978), Penser la Révolution Française. Paris, Gallimard / Folio Histoire.

GEFFRAY, Christian. (1995), Chroniques de la Servitude en Amazonie Brésilienne: Essai sur l'Exploitation Paternaliste. Paris, Karthala.

GERALDO, Endrica. (2009), “A ‘Lei de Cotas' de 1934: Controle de Estrangeiros no Brasil". Cadernos AEL, vol. 15, no 27, pp. 173-208.

GLUCKMAN, Max. (1958), "Analysis of a Social Situation in Modern Zululand". RhodesLivingstone Papers, № 28, Manchester, Manchester University Press.

MÉDECINS SANS FRONTIÈRES. (2010), “Operational Research: Definition, Purpose and Procedures". Luxembourg, Brussels Operational Center. 
MITCHELL, Clyde. (1966), "Theoretical Orientation in African Urban Studies", in L. Banton (org.), Anthropology Study of Complex Societies. London, Tavistock.

NOIRIEL, Gérard. (1988), Le Creuset Français. Histoire de l'Immigration-XIXe-XXe Siècles. Paris, Le Seuil.

OEA (ORGANIZAÇÃO DOS ESTADOS AMERICANOS). (1994), Cartagena Declaration on Refugees and Displaced Persons.

REVEL, Jacques. (1996), La Micro-analyse à l'Expérience. Paris, Seuil/Gallimard.

SAYAD, Abdelmalek. (1975), “El Ghorba: Le Mécanisme de Reproduction de l’Émigration". Actes de la Recherche en Sciences Sociales, vol. 1, no 2, pp. 50-66.

VIDAL, Dominique. (2011), “Le Culte de l'Humanitaire”. La Vie des Idées. Disponível em http:/ / www.laviedesidees.fr/Le-culte-de-l-humanitaire.html. Acesso em $30 / 3 / 2011$ 


\title{
RESUMO
}

Nem Refugiados, nem Migrantes: A Chegada dos Haitianos à Cidade de Tabatinga (Amazonas)

O artigo visa a analisar a migração de 4.000 haitianos entre o início de 2010 e março de 2012 em Tabatinga (Amazonas), como um "evento crítico" na história migratória recente do Brasil. Baseando-se no trabalho in situ de assistência da organização internacional Médicos Sem Fronteiras junto a esta população, o texto evidencia os limites da capacidade de resposta legal e operacional nos níveis municipal, estadual e federal. Este jogo de escala analítico permite ainda entender a convergência de elementos e circunstâncias que produziram a situação humanitária de Tabatinga. No momento em que o Brasil está entrando nas rotas de migração globalizadas, o artigo pretende contribuir para o debate sobre a reforma da política migratória brasileira.

Palavras-chave: migração; Haiti; Tabatinga; Amazônia

\author{
ABSTRACT \\ Neither Refugees, nor Migrants: The Arrival of Haitians to the City of \\ Tabatinga (Amazonas)
}

This article sets out to analyze the migration of 4,000 Haitians between the beginning of 2010 and March of 2012 in Tabatinga (Amazonas), as a "critical event" in the history of recent migrations to Brazil. Based on onsite work by the Doctors Without Borders international organization, this text highlights the limits of the legal and operational response at the municipal, state and federal levels. This scale-based analytical approach allows for a comprehension of the convergence of elements and circumstances, which produced the humanitarian situation in Tabatinga. At the very time Brazil enters global migration routes, this article intends to contribute to the debate on Brazilian migratory policy reform.

Keywords: migration; Haiti; Tabatinga; Amazonia 


\section{RÉSUMÉ}

Ni Réfugiés, ni Migrants: L'Arrivée des Haïtiens à la Ville de Tabatinga (Amazonie)

L'article se propose d'analyser la migration des 4.000 Haïtiens entre début 2010 et Mars 2012 à Tabatinga (Amazonie), comme un "événement critique" dans la récente histoire migratoire du Brésil. S'appuyant sur le travail in situ d'assistance de l'organisation internationale Médecins Sans Frontières avec cette population, le texte met en évidence les limites de la capacité de réaction juridique et opérationnelle dans les niveaux locaux, provinciaux et fédéraux. Ce jeu d'échelle analytique permet aussi de comprendre la convergence de facteurs et circonstances qui ont produit la situation humanitaire de Tabatinga. A un moment où le Brésil commence à entrer dans les rotes migratoires mondialisés, l'article vise à contribuer au débat sur la réforme de la politique migratoire brésilienne.

Mots-clés: migration; Haïti; Tabatinga; Amazonie

\section{RESUMEN}

Ni Refugiados, ni Migrantes: La Llegada de los Haitianos a la Ciudad de Tabatinga (Amazonas)

Este artículo busca analizar la migración de 4.000 haitianos entre principios de 2010 y marzo de 2012 en Tabatinga (Amazonas) como un "evento crítico" en la historia migratoria reciente de Brasil. Basándose en el trabajo in situ de asistencia desarrollado por la organización internacional Médicos Sin Fronteras junto a esta población, el presente texto evidencia los límites de la capacidad de respuesta legal y operacional en los niveles municipal, estatal y federal. Este juego analítico de escalas permite entender la convergencia de elementos y circunstancias que produjeron la situación humanitaria de Tabatinga. En un momento en que Brasil pasa a adentrarse en las rutas globalizadas de migración, el texto también pretende contribuir al debate sobre la reforma de la política migratoria brasileña.

Palabras clave: migración; Haití; Tabatinga; Amazonia 